\title{
Analysing the Speed-flow Relationship in Urban Road Traffic
}

\author{
M. Juhász ${ }^{1}$, Cs. Koren ${ }^{1}$, T. Mátrai \\ ${ }^{1}$ Széchenyi István University, Department of Transport Infrastructure \\ Egyetem tér 1, 9028 Győr, Hungary \\ Phone: +36 202333318 \\ e-mail: mjuhasz@sze.hu
}

\section{${ }^{2}$ Budapest University of Technology and Economics, Department of Transport Technology and Economics Múegyetem rkp. 3, 1111 Budapest, Hungary}

\begin{abstract}
In road traffic, speed-flow curves describe the relationship between vehicle flow rates and average vehicle speeds. These functions are one of the basic elements of transport modelling and they are widely used in project appraisal. Review and re-validation of speed-flow relationship has become timely in recent years as vehicle fleet changed, average traffic volumes increased and more comprehensive, automatic data collection became available. This study used the database of the road operator in Budapest to simultaneously analyse travel times and traffic volumes. The paper aims to examine the validity of the well-known fundamental diagram for urban roads, to provide an estimation for the speed-flow curve based on the Budapest case and to assess the on-set process of congestion.
\end{abstract}

Keywords: speed-flow relationship, transport modelling, urban road transport, congestion

\section{Introduction}

As the strategic planning and management of urban transport systems is a very complex issue, decision-makers should apply a comprehensive approach supported by different policy assessment tools. These instruments strive to take into consideration all the relevant aspects in order to assist "well-informed" decisions. A quite universal and widely accepted method in transport appraisal is cost-benefit analysis (CBA) which is assessing projects from an economic point of view. In order to carry out such analyses transport modelling methods are used to forecast travel behaviour and to estimate transport-related input values for the CBA (such as travel times, distances covered). [1]

In case of road traffic, speed-flow curves describe traffic states through the relationship between vehicle flow rates and average vehicle speeds for homogeneous mostly non-urban - road sections. In a converted form of this function, the so-called 
volume-delay function (VDF) describes the relationship of transport demand and average travel times on the road. VDF is the basis of traffic assignment models and underlying calculations, so it essentially influences the results of transport modelling and appraisal [2], [3].

In recent years the review of speed-flow relationship has become timely as vehicle fleet changed, average traffic volumes increased and more comprehensive, automatic data collection became possible [4]. The motivation for the review or update is to improve transport modelling methods and create more robust models. However, reviews are basically focused and constrained to non-congested states of road traffic, while the modelling of congestion would be the most interesting issue. It is another aspect that speed-flow curves are generally derived and validated on the road network used for long-distance, interurban travel, but urban transport and its strategic planning is becoming more and more important as the ratio of urban population is increasing. [5]

This study focuses exclusively on urban road transport. An initial research idea of the authors of this paper was to develop a forecast model for travel time reliability. That ongoing research uses the database of the road operator in Budapest to measure reliability. As an extensive dataset of travel times and traffic volumes is available, in this paper it was intended to carry out an in-depth analysis of urban speed-flow curves, with a special focus on congestion states. Therefore, the aim of this study is to:

- examine the validity of the well-known fundamental diagram (a standard form of the speed-flow relationship) for urban roads;

- provide an estimation for the speed-flow curve based on the data from Budapest;

- analyse the on-set process of congestion based on the speed-flow relationship.

\section{Methodology and data}

Expected values of travel times (or mean delays) can be described on a macro modelling level by VDFs. These long-standing functions are widely-used in transport modelling and are able to provide quite adequate estimations. However, some criticism exists surrounding the method and its application for urban areas. In spite of these shortcomings of VDF, a better way of estimation is still to be discovered. [6], [7], [8]

In an aforementioned research the authors of this paper studied the issue of forecasting travel time reliability for urban roads, and in the course of the analysis an essential question has arisen on whether the fundamental speed-flow diagram is valid for urban road traffic. During the research, some peculiar things have been noticed and that provided the motivation for this study which assesses the relationship between the saturation level (referred as F/C, the ratio of traffic volume and the capacity of the road, which is a universal parameter of traffic state) and the average travel times (or in a derived way: average speeds). To this end it was needed to simultaneously measure trip times and saturation level for given (preferably longer) urban routes. For the latter it is sufficient to measure the traffic volume as road capacity can be determined based on traffic engineering standards and planning guidelines. Due to the limitations of travel time measurements (travel time values were automatically rounded to minutes, which is 
not characterising shorter sections adequately), a whole route was analysed. Therefore, it was also needed to calculate an $\mathrm{F} / \mathrm{C}$ value for the route based on sectional values.

\section{Data - the case of Budapest}

In the case of the city of Budapest an opportunity presented itself to carry out the aforementioned experiment due to the implementation of the 'Easyway' project [9]. Within this ITS (Intelligent Transport System) development, automatic number plate recognition (ANPR) cameras and variable message signs were installed on the inner section of M1-M7 motorway and main road No. 6 in 2012, with the purpose of informing car drivers on the actual average access time of Danube bridges. Moreover, the affected area is fully covered with strategic traffic-counting detectors due to the long-lasting development of the traffic control system of Budapest. The measurement area is illustrated by Fig. 1.

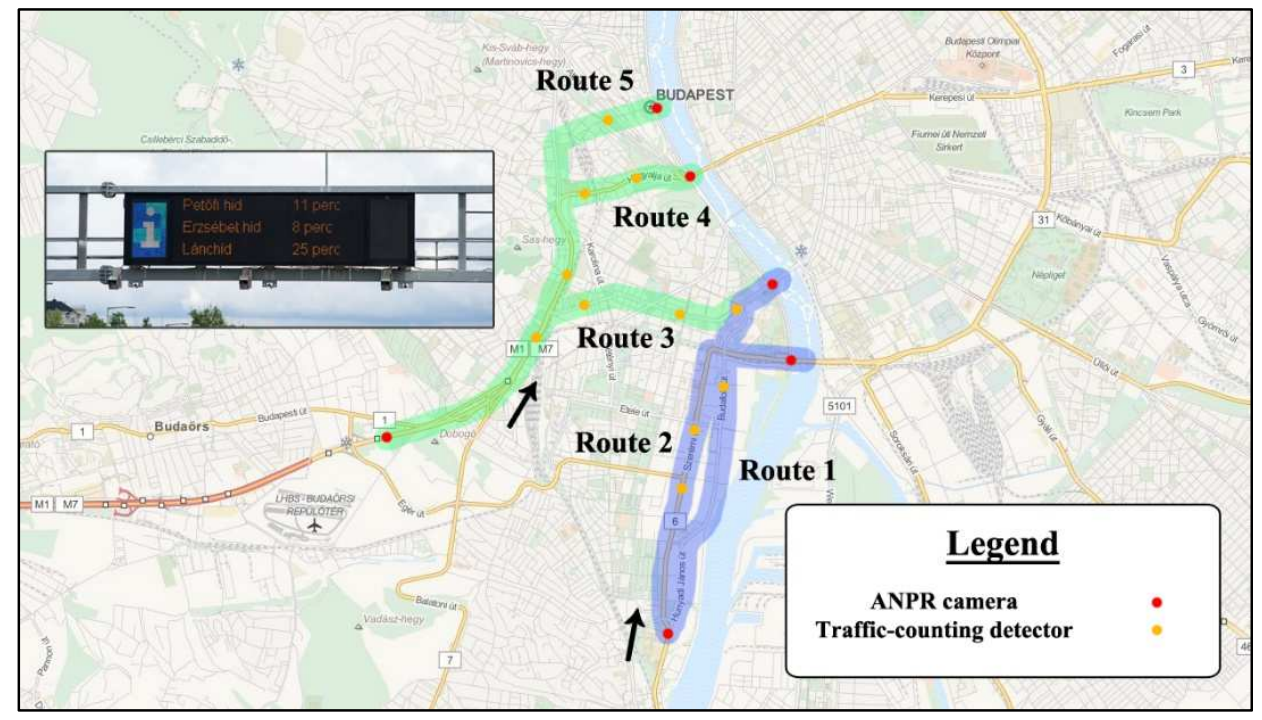

Figure 1. Map of the measurement area

To carry out the research the data of April 2014 was selected. For that month the total number of measurements is 525,000 (i.e. the number of trips for which both the travel time and the traffic volumes were registered). The measuring of travel times is automatic and classified to time intervals of 6 and 15 minutes for peak (4 a.m. -5 p.m.) and off-peak periods respectively. Traffic counting detectors use 4, 8 and 10-minutelong time intervals for peak (4 a.m. - 10 a.m., 12 a.m. -6 p.m.), intermediate (10 a.m. 12 a.m.) and off-peak (6 p.m. -4 a.m.) periods respectively.

\section{Methodology}

Transport modelling is always about to describe an average situation and therefore only general conclusions can be drawn from these models. It would be interesting to analyse the differences between various time periods (seasons, days), but as strategic macro modelling of transport mostly describes an average daily traffic, this research 
also intended to do so. To that end days from Friday to Monday have been filtered out from the sample.

First of all, the statistical solidity of each measurement was checked for both travel times and traffic volumes. It is important to note that the Easyway system automatically checks the measured data and filters wrong measuring from a statistical aspect. Some traffic counting locations needed to be excluded from the analysis due to failures or the detection of obviously wrong measurement. However, an abundantly sufficient amount of data remained for the analysis: both time segments of the daily traffic flow and the volume-capacity scale has been covered.

The most perceivable results were derived from route No. 4 (from the end of M1-M7 motorway to Erzsébet Bridge) in which all traffic counting detectors were in operation during the analysis period and road capacity values were also unambiguous to determine. Therefore, results of this study are presented based on this route. However, other routes were also studied in details and similar results were found, but different deficiencies and data errors cause some distortion and for most of the other cases results are not so clear than for the chosen one. For route 4 the travel time of around 80,000 car trips were available for the analysed 14 working days. Both to each $5 \%$ group of the volume-capacity scale and to each 'hour of the day' group at least 100 trips have been allocated.

Route 4 is about $6.1 \mathrm{~km}$ long, it is also adequate for analysis as this is a route which starts at the end of a motorway and ends in the city centre. It contains almost every type of road except minor roads and residential streets, but as congestion is basically relevant on major urban roads, speed-flow curves should be also estimated based on these road types. The speed limit is $70-100 \mathrm{~km} / \mathrm{h}$ for nearly the first half of the route and $50 \mathrm{~km} / \mathrm{h}$ for the inner sections. Along the way, there are six signalised intersections (with traffic lights working in a $24 \mathrm{~h}$ normal mode) and four locations with a non-signalised pedestrian crossing. As the inbound direction was scrutinized in this research, it is evident that congestion is more severe in the morning peak and slighter in the afternoon. Presumably those drivers use this route in the morning peak period who live in the southern-western suburban area of Budapest and whose destinations are in the city centre or in the eastern part of the city.

The first problem is that there is an essential difference between observed and modelled traffic volumes. The former represents the actual traffic which can be counted on the road, while the latter is a derived value expressing the demand, the number of those who intend to use the road. The issue can be well described with the fundamental diagram (originally based on [10] and [11]) and the standard VDF which is applied in transport modelling [2]. The task was to distinguish normal (not congested) state from congested state on the speed-flow curve. For instance, F/C value of 0.7 can mean 0.7 in modelling if it is in the normal state and a value above 1 if that is in a congested state. Then the problem is to find the proper $\mathrm{F} / \mathrm{C}$ value in a modelling sense which can adequately represent the given state.

Automatic and manual analysis of the dataset in a time sequence (going through each time step of the measurement) made it possible to distinguish normal and congested traffic states. The authors defined a classification according to Table 1. Any state was 
considered normal if the $\mathrm{F} / \mathrm{C}$ ratio and the mean travel time have changed in the same direction compared to the previous time step. In the fundamental diagram there are values for speed, but as the length of the route is given, journey times can be derived. Manual checks were only necessary in cases where the classifying algorithm was uncertain.

Table 1. Definition of normal and congested traffic states in the fundamental diagram

\begin{tabular}{|c|c|c|}
\hline \multicolumn{3}{|c|}{$\begin{array}{c}\text { Change of the characteristics of a time step } \\
\text { compared to the previous one }\end{array}$} \\
\hline $\begin{array}{c}\text { F/C (traffic flow / } \\
\text { capacity) ratio }\end{array}$ & $\mathrm{v}$ (mean speed) & $\mathrm{t}$ (mean travel time) \\
\hline \multicolumn{3}{|c|}{ Normal (not congested) state } \\
\hline$\uparrow$ & $\downarrow$ & $\uparrow$ \\
\hline$\downarrow$ & $\uparrow$ & $\downarrow$ \\
\hline \multicolumn{3}{|c|}{ Congested state } \\
\hline$\uparrow$ & $\downarrow$ & $\uparrow$ \\
\hline
\end{tabular}

The definition of congestion or congested states are often based on absolute or relative increase in travel times (e.g. in [12]). The problem is that congested speeds which are derived from congested travel times should not be analysed in a framework in which the state of congestion is defined on the value of the dependent variable (travel time). The definition applied in this research define normal and congestion states based only on the sign of the change of the analysed variables (speed and travel time), which ensures that the classifying model is not overdetermined in the previously mentioned way.

Another difficult step of the research was to calculate the $\mathrm{F} / \mathrm{C}$ ratio for the entire route in a given time interval. The reason for this is that traffic counting stations can only characterise a shorter route section. And if a congestion state starts to evolve in a section, it needs time to be able to detect it on other sections. This is a similar phenomenon to wave propagation which is well-known in traffic flow theory [13]. Along this route three different sections can be distinguished, which is characterised by traffic counting detector(s): one in the outer (upstream), one in the middle and one in the inner (downstream) section. Eventually, the maximum of sectional $\mathrm{F} / \mathrm{C}$ ratios were used to indicate the saturation level of a route as it was observed that differences between sections are limited to $15-20 \%$ and results seemed to be more reasonable in this way than taking the minimum or the average of $\mathrm{F} / \mathrm{C}$ ratios. The reason behind this is that there is a strong interdependence between these sections as if the outer section is heavily congested it can have more effect on the travel time then those sections where there are slight or no congestion. However, the location of the maximum sectional $\mathrm{F} / \mathrm{C}$ value could change over time and it is also worth to be analysed. 


\section{Results}

\section{On-set of congestion}

It was observed that congestion evolves quite rapidly but this can be fairly described with the standard speed-flow diagram. The typical situation is presented by the dataset of a typical working day (Thursday). The morning period ( 6 a.m. -12 a.m.) is showed in time steps of 6 minutes (with altogether 60 time steps). In Fig. 2 the changes of F/C values are illustrated. Fig. 3 shows the changes in average speed values. Congestion states have been highlighted with red colour between 7:15 and 9:30. Time represents the start of the travel time measurement for each trip, which is the time when the vehicle entered the studied route. Apart from that typical case, there may be some unexpected phenomena in which during the onset of the morning peak congestion can evolve from a moderately saturated state (e.g. a normal state characterised by an $\mathrm{F} / \mathrm{C}$ value of 0.7 turns into a congested state with a similar F/C value).

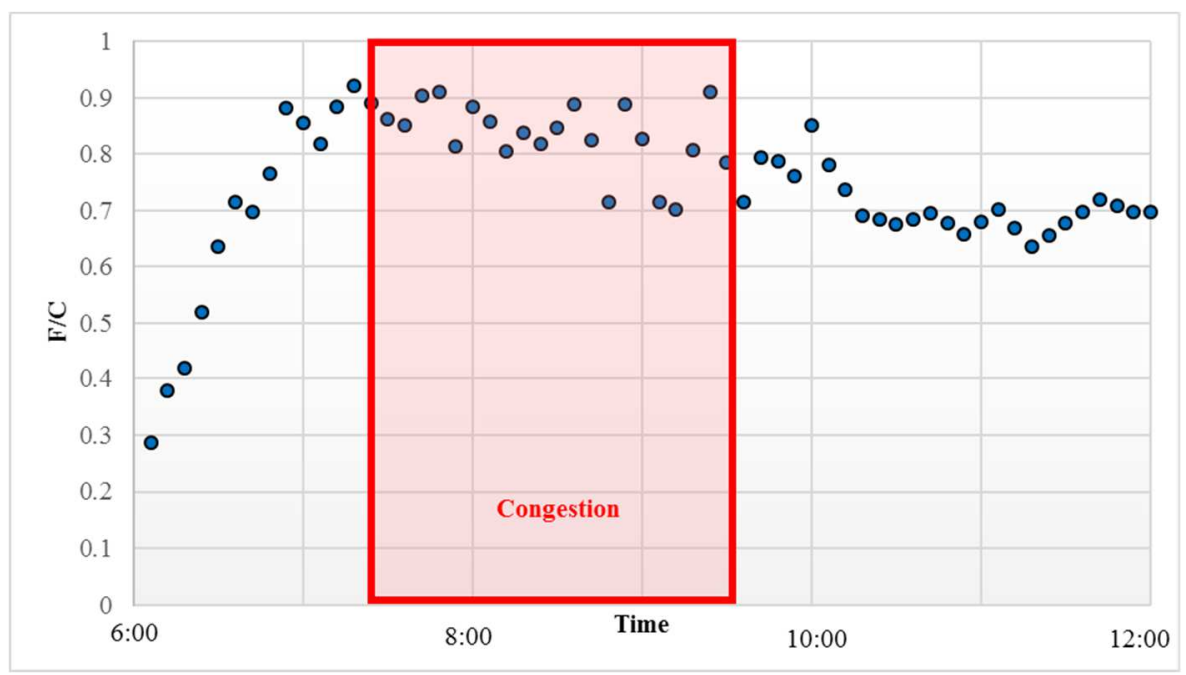

Figure 2. Changes of the saturation level in 6-min time steps on route 4 (6 a.m. - 12 a.m.) 


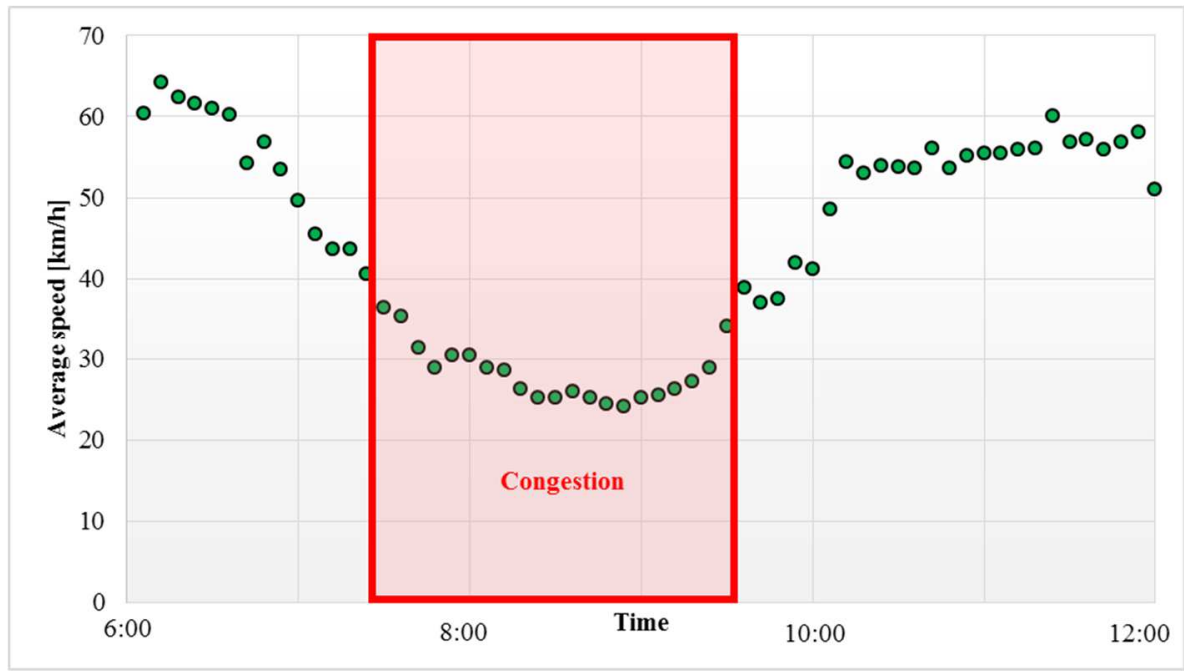

Figure 3. Changes of the average speed in 6-min time steps on route 4 (6 a.m. - 12 a.m.)

Based on these analyses quick transition states and a quite stable, homogeneous congestion state can be noticed. Both the on-set process and the recovery phase last 1520 minutes.

Fig. 4 presents the observed points of the speed-flow curve. The fundamental curve is not totally valid to describe the transition states or at least there are some odd features for $\mathrm{F} / \mathrm{C}$ values above 0.75 .

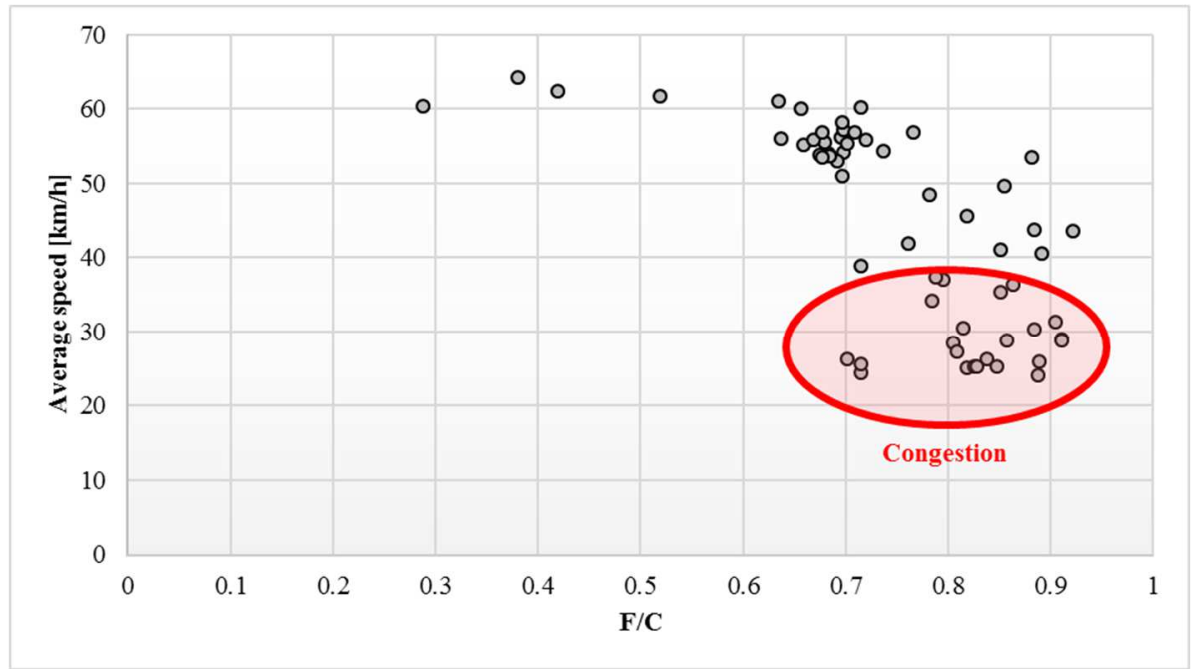

Figure 4. The relationship between average speed and the saturation level on route 4 (6 a.m. - 12 a.m.)

Two possible explanations could be assumed: 
- The analysis was carried out on a longer route and not on a homogeneous road unit, which could affect the results beside our conviction that urban transport systems should be analysed in their complexity;

- Urban road transport is a more complex phenomenon then non-urban and not only the speed limit is the difference but more comprehensive interactions between road users (e.g. intersections, traffic signals, pedestrian crossings, cyclists, etc.).

From the results it is clear that the previously introduced definition of congestion states is in line with the measured speed values which are under $35-38 \mathrm{~km} / \mathrm{h}$ in the course of congestion. Having analysed the location of the maximum $\mathrm{F} / \mathrm{C}$ value from the sectional data it was found that it is mostly coming from the midway section. However, during the on-set stage the maximum value is on the inner (downstream) section and congestion spreads outwards, while during the recovery the outer (upstream) section is the most congested [14], [15]. These data show that the congestion on-set starts downstream and it travels backwards, while the recovery starts upstream and it moves forward.

It should be also noted that there are a number of entering and diverging roads along the analysed route which may influence the results. Anyway, valuable results highlight the quality of the applied methodology.

\section{Speed-flow relationship for urban roads}

Normally, the preliminary expectation would be that a $0.7 \mathrm{~F} / \mathrm{C}$ ratio represents a more severe congestion state than a ratio with a value of 0.8 , but due to the on-set and the recovery of congestion states it is not necessary true. Fig. 5 shows that there are two distinct on-set processes of congestion: the standard and the previously presented way in which the there is a quicker transition to congestion (red and yellow respectively on the left side of the figure). Both the former and the latter can be observed in morning and afternoon peak hours on route 4 , but the former was much more frequent. Similarly, there are two ways of congestion recovery (green and yellow on the right side of the figure).

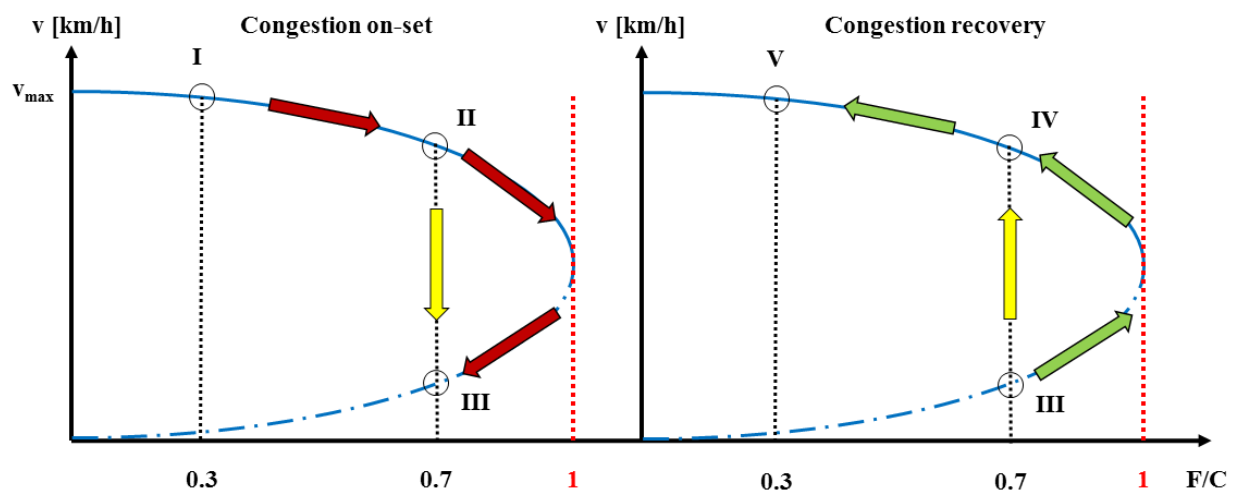


Figure 5. Ways of congestion on-set and recovery illustrated on the fundamental diagram

Then the question is how can the speed-flow curve for urban road traffic be described and how can the difference between observed and artificially modelled $\mathrm{F} / \mathrm{C}$ be handled. Observed $\mathrm{F} / \mathrm{C}$ values cannot be higher than 1 , but in a modelling sense congested states are measured with values above 1 as traffic volume is measured by the demand in a transport model.

First of all, there was no evidence on congestion states characterised by a saturation ratio under 0.5 (see Fig. 6), so this part of the speed-flow curve is not relevant for estimation. Secondly, in on-set transition periods it was really difficult to distinguish normal and congestion states of traffic, so transition data points (with $\mathrm{F} / \mathrm{C}$ values between 0.7 and 0.85 ) may somewhat distort the speed-flow curve estimation. The data was grouped based on the $\mathrm{F} / \mathrm{C}$ ratio by $5 \%$. Then mean travel time and average speed values were calculated for each $\mathrm{F} / \mathrm{C}$ group with the separation of normal and congested states (based on the rules of Table 1). As a result, the relationship between the saturation level and the mean average speed can be presented (Fig. 7).

Fig. 6 shows the long-drawn on-set of the morning congestion between 7 a.m. and 10 a.m. The morning peak hour is generally starts around 7 a.m. with a typical travel time of 13-15 minutes. After the morning peak travel times remain at a consolidated level of 7-8 minutes with $\mathrm{F} / \mathrm{C}$ fluctuating between 0.5 and 0.85 . The afternoon peak (4 p.m.) is quite speedy and firm. Then for the evening the mid-day state is restored.

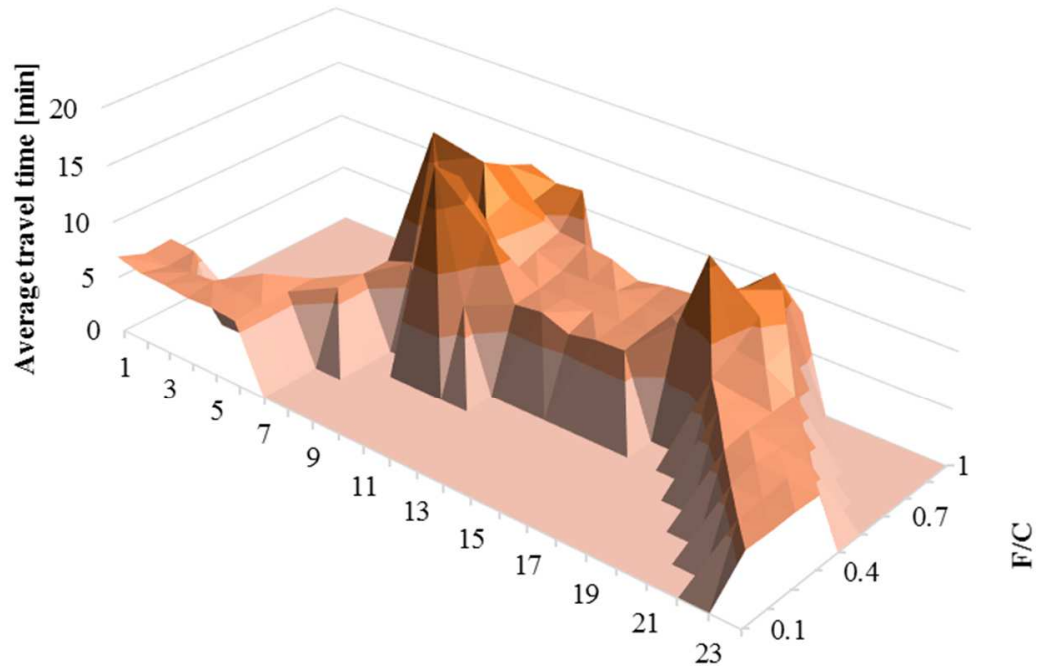

Hour of the day

$\square 0-5 \square 5-10 \square 10-15 \square 15-20$

Figure 6. The average travel time according to the time of the day and the saturation level for route 4 (14 working days in April 2014) 


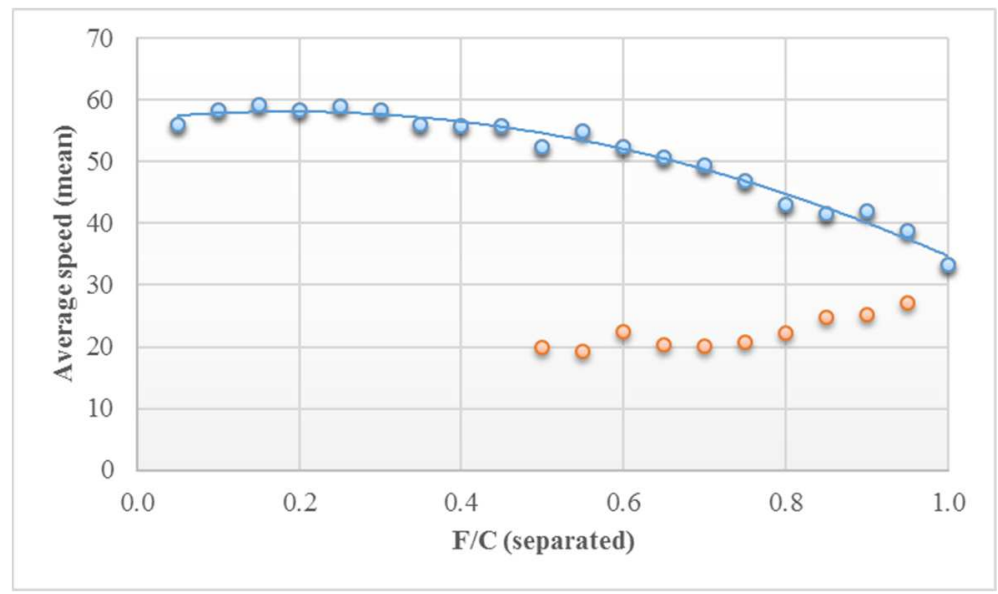

Figure 7. The relationship between the saturation level and average speed for route 4 (14 working days in April 2014)

For normal and congested traffic states different curves can be fitted based on equation (1) in which $\mathrm{F} / \mathrm{C}$ is the saturation ratio between 0 and $100 \%$. The estimated parameters can be found in Table 2 .

$$
v_{\text {cur }}=\mathrm{a} * \frac{F^{2}}{C}+\mathrm{b} * \frac{F}{C}+v_{\max } .
$$

Table 2. Estimated parameters of fitted speed-flow curves

\begin{tabular}{|c|c|c|c|c|}
\cline { 2 - 4 } \multicolumn{1}{c|}{} & $\mathrm{a}$ & $\mathrm{b}$ & $\mathrm{V}_{\max }$ & $\mathrm{R}^{2}$ \\
\hline Normal (not congested) state & -35.3 & 13.1 & 56.94 & 0.97 \\
\hline Congested state & 50.1 & -57.5 & 36.54 & 0.86 \\
\hline
\end{tabular}

This equation is valid for the whole route and not necessarily valid for its shorter sections with different technical parameters. Appropriate equations for shorter homogenous sections can be found in different studies (e.g. in [6]). The $v_{\max }$ values is different for each route and for the normal state it can be approximated by 0.85 times the weighted average speed limit (for this route the weighted average was $67 \mathrm{~km} / \mathrm{h}$ ). For the congested $\mathrm{v}_{\max }$ a good approximation could be to use the multiplier of 0.55 .

Regarding the representation of congested $\mathrm{F} / \mathrm{C}$ values in a modelling sense a "mirror" function can be defined. Based on the analysed cases and VDF estimation experiments it was found that equation (2) can well describe the modelling $\mathrm{F} / \mathrm{C}$ value. Within the equation $\mathrm{F} / \mathrm{C}_{\mathrm{mod}}$ and $\mathrm{F} / \mathrm{C}_{\mathrm{obs}}$ are the modelling and observed $\mathrm{F} / \mathrm{C}$ values respectively only for congested states, while ' $c$ ' is a correction parameter with an estimated value of 1.2.

$$
F / C_{\text {mod }}=1+\frac{1-F / C_{o b s}}{c}
$$

In the course of this whole research (including the one on travel time reliability) in which a VDF was also calibrated, the maximum modelling $\mathrm{F} / \mathrm{C}$ value (demand-capacity ratio) was 1.4 which represented the $\mathrm{F} / \mathrm{C}$ point of around 0.5 on the observed speed-flow curve (see Fig. 8). 


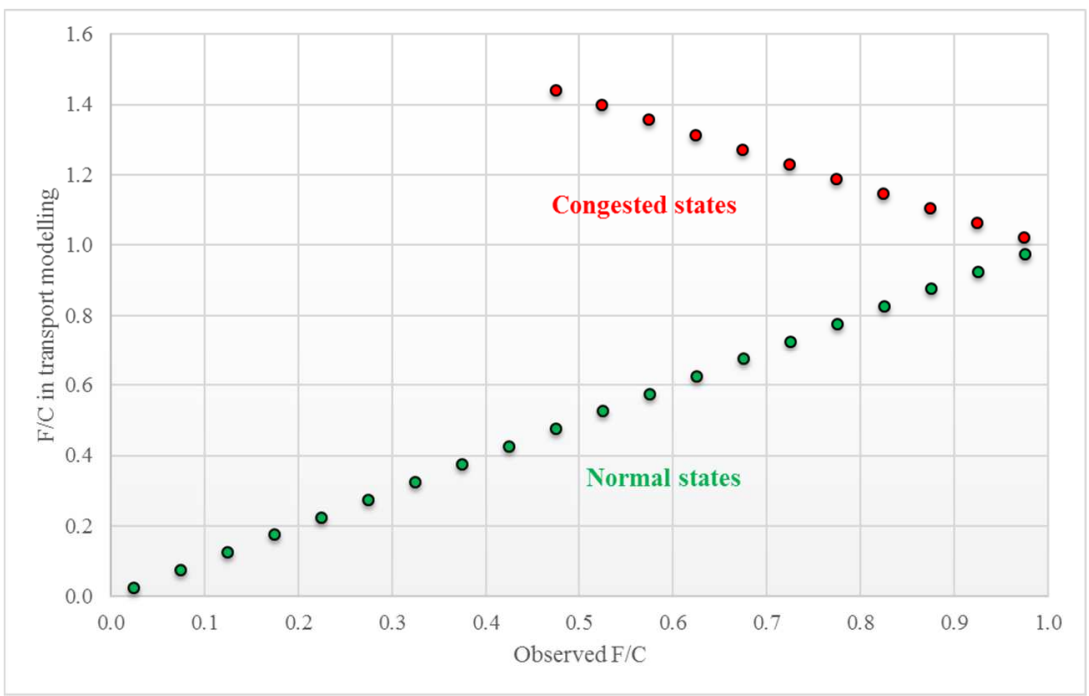

Figure 8. The relationship between the observed and transport modelling $F / C$ value based on the VDF calibration of route 4

\section{Conclusions}

The analysis of the relationship between traffic flows and speeds is essentially important since it is the basis of several methods in transport modelling (e.g. calculation of route impedances in assignment models). This study pointed out that the fundamental diagram can be valid for urban roads as well, but it might be used with some restraints for transition states between normal traffic and congestion. The main findings are the following:

- Different states on the fundamental diagram can be identified based on indicator (speed or travel time and $\mathrm{F} / \mathrm{C}$ ) changes in order to distinguish normal and congested states. In other words, the fundamental diagram can be valid in urban conditions as well, although some deviation is possible.

- Congestion can evolve in a rapid way with moderate $\mathrm{F} / \mathrm{C}$ value; therefore two types of congestion onset mechanism can be differentiated.

- In case of congested urban conditions, the speed is practically independent of the saturation level, travel times are nearly homogeneous and only minor differences can be identified.

However, an estimation has been provided for the speed-flow states based on the Budapest case. As the onset and release of congestion can happen in a relatively short time, a specific modelling method can be proposed, where a day is segmented to 5 different time periods where different volume-delay functions apply. Analyses like this one are badly needed to check the extensibility of this research (e.g. other locations, time periods). 


\section{Acknowledgement}

This research was supported by Gergely Rónai (Budapest Közút Plc.) with his help regarding the acquisition of data.

\section{References}

[1] Mátrai T. Cost benefit analysis and ex-post evaluation for railway upgrade projects: Ex-post economic evaluation, evaluation of traffic disturbance during construction and evaluation of travel time variability. Instituto Superio Technico, 2012

[2] Ortúzar J de D, Willumsen LG. Modelling transport. 4th Editio. Chichester: John Wiley \& Sons Ltd, 2011

[3] Akçelik R. travel time function for transport planning purpose: Davidson's function, its time-dependent form and an alternative travel time function. Aust Road Res 2000, No. 3, pp. 49-59, 2003

[4] Rao AM, Rao KR. Free speed modeling for urban arterials - A case study on Delhi. Period Polytech Transp Eng, Vol. 43, pp. 111-9, 2015 DOI: 10.3311/PPtr.7599

[5] United Nations. World Population Prospects: The 2015 Revision, Key Findings and Advance Tables. New York: 2015

DOI: ESA/P/WP.241

[6] Woollett N, Vaughan B, Lunt G. Re-validation of speed/flow curves. Proc. Eur. Transp. Conf., AET; 2015

[7] Vasvári G. Additive Effects of Road Functions. Period Polytech Civ Eng, Vol. 59, pp. 487-93, 2015

[8] Vasvári G. Volume-delay functions of minor junctions created by microsimulation. Pollack Period, Vol. 9,pp. 29-40, 2014 DOI: 10.1556/Pollack.9.2014.1.4

[9] BKK. Easyway projekt - digitális kijelzök 2012. http://www.bkk.hu/fejleszteseink/easyway-projekt/ (accessed January 5, 2016).

[10] Greenshields BD, Bibbins J, Channing W, Miller H. A study of traffic capacity. Highw Res Board Proc, pp. 448-477, 1935

[11] Stamos I, Maria J, Grau S, Mitsakis E, Mamarikas S. Macroscopic fundamental diagrams: simulation findings for Thessaloniki's road network. Int J Traffic Transp Eng, Vol. 5, pp. 225-37, 2015

DOI: $10.7708 /$ ijtte.2015.5(3).01

[12] Börjesson M, Eliasson J. Train Passengers' Valuation of Travel Time Unreliability. Eur. Transp. Conf., pp. 1-16, 2008

[13] Daganzo CF. Fundamentals of Transportation and Traffic Operations. Emerald, Inc.; 2008

[14] Knockaert J, Verhoef ET, Rouwendal J. Bottleneck congestion: Differentiating the coarse charge. Transp Res Part B Methodol, Vol. 83, pp. 59-73, 2016 DOI: $10.1016 /$ j.trb.2015.11.004

[15] Gramaglia M, Trullols-Cruces O, Naboulsi D, Fiore M, Calderon M. Mobility and connectivity in highway vehicular networks: A case study in Madrid. Comput Commun, Vol. 78, pp. 28-44, 2015

DOI: 10.1016/j.comcom.2015.10.014 